\title{
Static infographics effects on the receptive knowledge of idiomatic expressions
}

\author{
Assim S. Alrajhi \\ Department of English Language and Translation, College of Arabic Language and Social Studies, \\ Qassim University, Saudi Arabia.
}

\begin{abstract}
Idiomatic expressions are essential components of EFL learners' linguistic repertoire. Nevertheless, learning such inherently perplexing language constructs poses a challenge to learners. Therefore, the present study was motivated by examining a modern tool (infographics) that is relatively under-researched in EFL settings and potentially conducive to fruitful vocabulary learning. Grounded in dual coding (DCT) and cognitive load (CLT) theories, this study aims to examine the effectiveness of visualizing English idioms via static infographics. Data were collected using three instruments (a pre-/post-test, an attitude questionnaire, and semi-structured interviews) in a mixed-method design. The participants consisted of 78 Arabic speaking students at a Saudi university. Divided equally into two groups, these participants were instructed to learn 60 idioms in five computer-mediated sessions. Students in the control group studied the target idioms via online texts, whereas those in the experimental group studied them via online static infographics. The findings show that despite the significant increase in the post-test scores of both groups, the treatment group outperformed the control group as indicated by the statistically significant difference in scores. Consequently, the findings signify a high potential of static infographics to foster receptive knowledge of idioms. Moreover, the participants show positive attitudes toward the utility of static infographics on learning idioms. Meanwhile, the qualitative findings reveal a number of compelling factors induced by productive constituents and adequate content of the infographics. Those factors are conducive to effective learning and retention, triggering motivation and interests, promoting autonomous and efficient learning, and attracting learners' attention.
\end{abstract}

Keywords: EFL learners; idiomatic expressions; infographics; L2 learning, vocabulary

\section{First Received:}

5 May 2020

Final Proof Received:

27 September 2020

\section{Revised:}

28 August 2020

\section{Accepted:}

21 September 2020

Published:

30 September 2020

Alrajhi, A. S. (2020). Static infographics effects on the receptive knowledge of idiomatic expressions. Indonesian Journal of Applied Linguistics, 10(2), 315-326. https://doi.org/10.17509/ijal.v10i2.28596

\section{INTRODUCTION}

The pivotal role of vocabulary in second language (L2) learning and development has been wellestablished in L2 research (Astika, 2018). Among the constituents of L2 vocabulary that L2 learners encounter in both oral and written communication are idiomatic expressions, and learning of those expressions are considered important for L2 learners. However, the teaching and learning of idiomatic expressions poses a serious complication to L2 learners (Bakla et al., 2016). In spite of the efforts in language research that have examined the potential of several approaches, methods, and tools to enhance the outcomes of idioms learning, this area has not received sufficient attention (Cieślicka, 2006). According to Alali and Schmitt (2012), there has been a paucity of research investigating possible optimal methods for teaching formulaic sequences, of which idioms are a component. Among the tools that might have a potential to overcome the challenges of teaching and learning idiomatic expressions are infographics. 
The present study is grounded in Dual Coding (DCT) and Cognitive Load (CLT) theories. It proposes that infographics enable users to visualize the content and receive input through a combined presentation of information using images and text. Therefore, they engage the user in several levels of information processing according to the Dual Coding theory (Paivio, 1971, 1986), and contribute to decrease the overwhelming cognitive load based on the Cognitive Load theory (Sweller, 1988; Sweller et al., 1998). Research that has scrutinized L2 idioms learning via infographics is scarce. Therefore, this study seeks to investigate the potential of this tool that might lead to fruitful learning outcomes and a more effective approach to tackle the perplexity of learning such a challenging language pattern.

\section{Categorizing idioms and the conundrum of definition}

Research in the area of idiomatic expressions has often faced the perplexity of precisely defining this construct (Liu, 2008). Nonetheless, several different definitions of idioms have been proposed by researchers such as Irujo (1986), and Boers et al. (2014), to name just a few. A commonly shared aspect in the proposed definitions is that what constitutes an idiom is the unique characteristics of signaling a whole meaning as one unit that is distinct form the meanings suggested by the constituents of the idiom. Such a consensus of this core aspect of idioms is also problematic, as some idioms can be deducible from their constituents.

Categorizing different types of idioms does not appear to be definitive in literature. However, idioms have commonly been categorized into the degree of their transparency, familiarity, and compositionality: transparency refers to the propinquity between the non-literal and literal meaning; familiarity or frequency describes how frequent an idiom can be found in language (Nippold \& Taylor, 2002). In terms of compositionality, indecomposable idioms refer to those expressions that their individual components (words) meaning cannot reveal the intended meaning of the expression (Velasco, 2016).

\section{Idioms and L2 learners}

Idioms are pervasive in English language (Zuo, 2020). Hinkel (2017) emphasized that due to their ubiquity in language, learning and teaching of idioms is vital for communication. The importance of learning idioms stems from several reasons such as learning and understanding the target language speakers' culture (Liontas, 2017), enhancing receptive and productive competences that can highly support L2 learners in a multitude of different settings (Hinkel, 2017), and, as multi-word units, they support fluent production of language since they demand less cognitive processing than producing new units of utterance (Schmitt, 2000).

\section{Idiom instruction and the effect of images}

Research has explored potential approaches to teach idioms, ranging from a traditional approach such as Alali and Schmitt (2012), to a cognitive linguistic approach such as Hung (2019), and the study of Bakla et al. (2016) that included examining the utility of pictorial illustrations. Other studies have investigated the integration of images into idioms learning such as Szczepaniak and Lew (2011) that found evidence supporting the integration of images with text to foster idioms learning. Their findings suggested that employing images can support retention of forms and meanings. Vaez-Dalili et al. (2017) explored the effects of the availability of context, lack of context, and image cues on learning opaque and transparent idioms. Their findings showed that the use of image cues was the most effective. Furthermore, Abbasi et al. (2015) reported, following a comparison of the use of translation, definitions, and images to teach English idioms, that the use of images rendered better learning outcomes. In terms of the manner in which idioms are presented, Irujo (1986) contended that grouping idioms around particular themes is advantageous, as it both facilitates learning and aids teachers to group learning activities around particular topics.

\section{Grounding infographic design in theories of cognition}

The dual coding theory (Paivio, 1971, 1986) suggests that a double mode of presenting information through verbal (language) and visual (objects) input can foster learning. Accordingly, mental representation of information by both modes can occur, resulting in two different codes; thus, the possibility of recalling any input that is represented and processed in both modes can be higher compared to a single-mode input. Although processing of information in both modes is interconnected; however, each mode is separated and independent. Accordingly, infographic design that comprises language and images can facilitate a dual coding representation of the target idioms.

The cognitive load theory (Sweller, 1988) refers to the extent of utilizing the capacity of humans' working memory. Cognitive load can be categorized into intrinsic load (the extent of difficulty posed by a task), extraneous load (how content/information is presented to users/learners), and germane load (processing, formalizing, and internalizing information (Sweller et al., 1998)). As the extraneous load is associated with instructional materials and design, Sweller et al. (1998) contended that decreasing extraneous load and increasing germane load can be contrived and directed by instructional designers. Therefore, it is 
assumed that a infographic design with its limited content and different modes of presenting information can reduce the extraneous load and maximize the germane load.

\section{Infographic design and the multimodality of presentation}

An infographic forms a visual display of information that enables users to visualize and read concise pieces of information often within one single page. According to Lamb and Johnson (2014), some of the purposes of using infographics are to organize information meaningfully, to render information enjoyable to read and view with the use of text plus other elements, and to render meaningful information by using themes and examples. There are different types of infographics ranging from interactive to static, where the latter refers to presenting all data via a static image. In their study, Yildirim et. al (2016) found that there are six factors that contribute to the effectiveness of using infographics in education. Infographics enable learners to comprehend learning materials in a simple and successful manner compared to plain texts because they lend themselves well to the preferences of learners due to the inherent visual component. Infographics are simple, as the simplicity in their design provides limited information that increases motivation to engage users in reading infographics, and infographics increase retention of information. Similarly, Islamoglu et. al (2015) noted some effects of infographics on learning experiences.

Since infographics integrate images, colors, and texts within one entity, Smiciklas (2012) pointed out that images processing in the human brain can occur instantly; however, text processing might demand a longer period of time. One of the defining characteristics of infographics is that they provide visual stimuli. Çetin and Flamand (2013) argued that utilizing visual stimuli are assumed to draw attention, arouse interest, and facilitate retention. Moreover, Bradshaw and Porter (2017) pointed out that information that is visualized can influence the emotional side of individuals, as people instantly react to images and seek extra data when they are displayed in a simple, emotional arousing manner-images.

Examining infographic design by looking into the above samples of infographics used in the current study, there are a number similar elements in all the infographics. There are: (1) a specific background color for the presented infographic, (2) idiomatic expressions with textual enhancement, (3) images that reflect the meaning of the idioms, (4) verbal definitions of the idioms, and (5) one example where the target idiom is used.

Analyzing the design from a semiotic standpoint, the whole static infographic as a single image and images included for each idiom have particular functions representing a sign, signifier, and signified that communicate specific messages to infographic users.

For instance, in infographic $\mathrm{A}$, the main signifier presents the infographic as a whole as theme-based and relevant to Fall idioms. For individual idioms, the first signifier shows two leaves with different colors indicating a state of turning over or change (signified). Thus, when reading the accompanying idiom and looking at the image, the signified (mental concept) facilitates grasping the meaning of the figurative idiom. By the same token, in infographic B, the main signifier presents the infographic as theme-based and relevant to Weather idioms. For individual idioms the second signifier suggests the sun and clouds, as showing different conditions (signified). Thus, when viewing the accompanying idiom and viewing the image, the signified (mental concept) facilitates comprehending the meaning as relevant to a behavior in different conditions. Therefore, images role in infographics is crucial for effective presentation of the contents; images reflect the meaning of the target idiom partially or completely.

Examining two types of cognitive styles (verbalizers and visualizers), Massa and Mayer (2006) concluded that verbalizers were inclined to seek verbal support to better understand information, whereas visualizers were inclined to utilize images to comprehend information. Additionally, research has indicated that a visualbased presentation of information might not render optimal outcomes compared to a visual-verbal presentation (Boers \& Lindstromberg, 2009). Brunye et al. (2008) noted that a multimedia-based presentation facilitates retention of the learned content as verbal and visual memories are simultaneously activated.

By and large, some research findings have suggested a facilitative role of infographics for learning purposes. For example, in a study that targeted the use of infographics in an anatomy course, Ozdamli et al. (2016) concluded that infographics was effective in assisting learners' comprehension of the content. Furthermore, exploring the power of infographics in English instruction, Al Hosni (2016), found effects of this tool on understanding the learned content and retention of information. Additionally, Akbarov et al. (2018) explored the perceptions of EFL learners regarding the use of infographics in blended learning, finding that, generally speaking, learners showed relatively positive attitudes toward the employment of infographics.

\section{Purpose of the study and research questions}

According to Afify (2018), few studies have examined how infographics can improve learning outcomes. In addition, idioms learning and instruction has not received ample attention, given 
that the relevant studies have not yielded clear practical implications (Liontas, 2015). Furthermore, research that has explored EFL learners' attitudes toward the use of infographics for learning English idioms is scarce. Therefore, this study aims to examine the potential of infographics to support idioms learning. To that end, this study aims to test the following hypothesis: learning English idioms by viewing static infographics is more effective than learning the same language construct through viewing texts. Additionally, this study seeks to investigate students' attitudes toward learning idioms via infographics, and to explore students'

\section{Figure 1}

Infographic Examples

Infographic A

\section{\{FOUR\}}

To turn over a new leaf

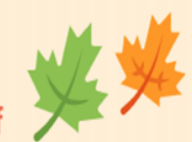

To begin again with better behavior than before.

I used to eat junk food but I turned over a new leaf after I had a heart attack.

\section{\{FIVE\}}

\section{The apple never falls far from the tree}

When someone looks or behaves like their parents or relatives.

I heard Sarah is going to the same law school where her parents met. The apple never falls far from the tree.

Infographic C

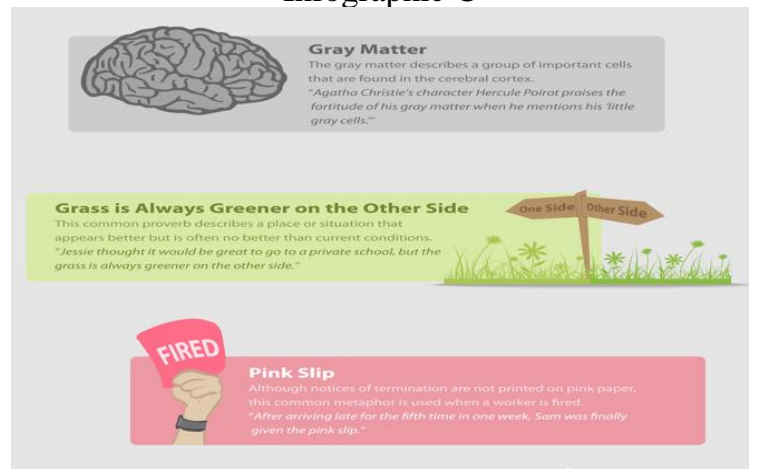

\section{METHOD}

\section{Participants}

The sample comprised 78 male Arabic speaking students enrolled in an English and Translation bachelor's program at a Saudi university. The biodata showed that the ages ranged from 19-26 (M $=21.96, S D=1.53$ ). Each group of the participants attended a 3-hour core class that meets once a week and was taught by the researcher. The students attended the classes in a fully-equipped language lab, were equally divided between the control $(n=$ $39)$ and experimental $(n=39)$ groups, participated in all experiment phases voluntarily, and 6 of whom

learning experiences with the use of infographics. Therefore, three research questions are posed:

1. Does the learning of English idioms via static infographics lead to improvement in the receptive knowledge of idioms compared to learning through texts?

2. What are EFL learners' attitudes toward the utility of static infographics on learning English idioms?

3. How have EFL learners experienced the use of static infographics to learn English idioms, and how does the design of the constituents of static infographics influence idioms learning?

Infographic B

ALL IN A FOG
confused
ex. When we saw Michael that evening, he was all
in a fog about what to do.
COME RAIN OR SHINE
no matter what
ex. Now, are you sure you will come?
Yes, definitely, I will be there come rain or shine.
CAST A CLOUD OVER
ruin, depress
ex. I don't want to cast a cloud over your holiday
plans but the weather forecast isn't great.
WEATHER THE STORM
get through a difficult situation
ex. The financial crisis that started in 2007 wasn't
a pleasant experience for anyone but somehow
the company weathered the storm.

Infographic D

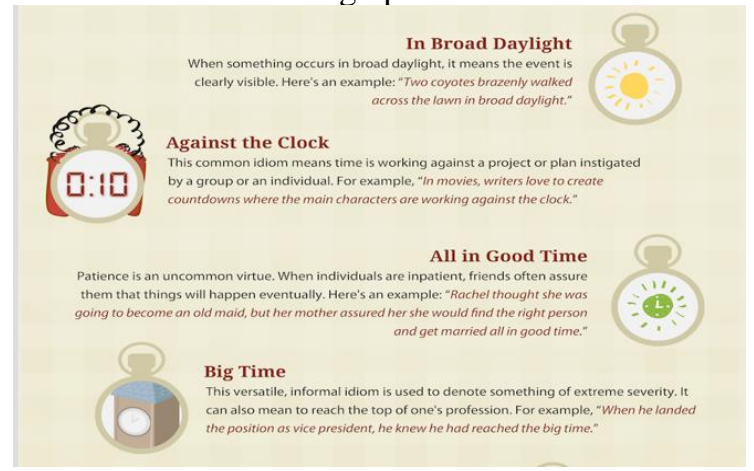

agreed to be interviewed, given that consent forms were secured prior to initiating data collection.

\section{Research design}

This study used a blend of qualitative and quantitative methods to collect data. The design comprised three instruments that were developed by the researcher: a pre-/post- recognition tests, an attitude questionnaire, and semi-structured interviews. Furthermore, the design consisted of five computer-mediated learning sessions. After the submission of the post-test, the students in the treatment group completed an attitude questionnaire, and were invited to the interviews. 


\section{Procedures and instruments}

All procedures were performed in an online environment, and data were collected in six weeks. Hyperlinks for the two tests, the questionnaires, and the learning sessions were distributed to the students via Blackboard (a virtual learning environment) to which all the participants had direct access during the time in which data were collected.

\section{Pre-/post-test}

A multiple-choice questions test (Appendix A) was developed by the researcher and piloted to a small sample. The internal consistency (Cronbach's $\alpha=$ .728 ) indicated a sufficient reliability of the test items. During the first week of the experiment, a 30item pre-test was administered to both groups that took the form of sentences that included idioms and four choices for each sentence offering possible meanings of the idioms. The participants used computers in the language lab to take the test. In each group, the pre-test lasted for around 40-45 minutes. Following the fifth session, the same test was immediately administered to both groups and lasted for around 35-40 minutes. The internal consistency (Cronbach's $\alpha=.879$ ) indicated a high reliability of the test items in the post-test. The preand post-tests were administered to the participants using Google Forms platform. Analysis of students' mean scores, different learning gains was run by utilizing SPSS v. 24.

\section{Attitude questionnaire}

The researcher developed an 11-item attitude questionnaire to elicit the participants' responses in the treatment group regarding idioms learning via infographics. The questionnaire took the form of a four-point Likert scale with (strongly agree $=4$ ), $($ agree $=3),($ disagree $=2)$, and (strongly disagree $=$
1) respectively. The items targeted several dimensions of the use of infographics to learn idioms such as easiness, innovation, attention, design, motivation, independent learning, retention, visualizing content, effectiveness, and efficiency. Internal consistency analysis rendered an adequate reliability (Cronbach' $\mathrm{s} \alpha=.700$ ) of the questionnaire items. The questionnaire was administered to the participants using Google Forms platform. Responses to the questionnaire lasted for around 12-15 minutes. For data analysis, SPSS v. 24 was used to obtain descriptive statistics.

\section{Semi-structured oral interviews}

The interviews concentrated mainly on the students' experiences of learning idioms via infographics. Moreover, the questions in the interviews sought to find out in-depth details about the findings of the attitude questionnaire. The interviewees were asked several questions such as: How do you describe your experience of learning idioms via infographics? What are some advantages and disadvantages of learning idioms via infographics? How do you comment on the following: autonomous learning, retention, elements of infographics design (less text, colors, and images). Each interview lasted for around 25 minutes.

\section{Learning sessions and materials}

The participants learned 60 target idioms in which each session consisted of a group of idioms organized around one of seven different themes (health, weather, clothing, ocean, color, fall, and time). The idioms presented to the students were categorized according to their degree of compositionality (Table 1), as whether they render literal meaning or figurative meaning.

Table 1

Categories of Idioms in This Study According to the Degree of Compositionality

\begin{tabular}{ll}
\multicolumn{1}{c}{ Literal } & \multicolumn{1}{c}{ Figurative } \\
\hline Ex: The calm before the storm & Pink slip \\
Ex. In sentence: She hasn't mentioned our bad results yet, & Ex. In sentence: After arriving late for the fifth time in one \\
I'm sure it's just the calm before the storm. & week, Sam was finally given the pink slip.
\end{tabular}

Ex: Take a turn for the worse

Ex. In sentence: The surgery itself went very well but she took a turn for the worse after she contracted pneumonia while recovering in the hospital.

Moreover, the majority of the used idioms were categorized as figurative. Presenting a large number of figurative idioms is suitable for the purpose of the study as to examine the power and facilitative role of infographics to tackle idioms learning and in particular the figurative ones, as they are considered to be the most challenging types of idioms. Each learning session lasted for around 3545 minutes. Students viewed the idioms meanings, examples, and did the exercises at their own pace.

\section{Ex: At the drop of a hat}

Ex. In sentence: My boss always expects me to be available at the drop of a hat even on weekends 
The exercise took the form of fill-in the blank in which the students read sentences that included missing idioms and had to fill in with an idiom from the ones they viewed. In contrast, the treatment group learned idioms in each session via an infographic that was shown in a website. The following procedures for the treatment group were exactly the same as the control group by using the aforesaid blog.

\section{Criteria for idioms and infographics selection}

Seven infographics and 60 idioms were selected by the researcher. The selection of idioms was mainly based on the availability of grouping them under a single theme. The infographics, as shown in Figure
2, were selected by extensive online searching, and the criteria for their inclusion were as follows: (1) infographics should depict English idioms; (2) infographics should be organized around single themes; (3) infographics should include a reasonable number of idioms to learn in one session; (4) infographics should contain a simple definition, one example, and an image for each idiom, and (5) students' familiarity with the depicted idioms should be at the lowest levels, which can be clearly indicated by the pre-test mean scores. In terms of the design, the infographics were relatively similar and textual enhancement was evident in all the selected infographics: bold typeface for idioms and background colors for the infographics.

\section{Figure 2}

Samples of the Used Infographics
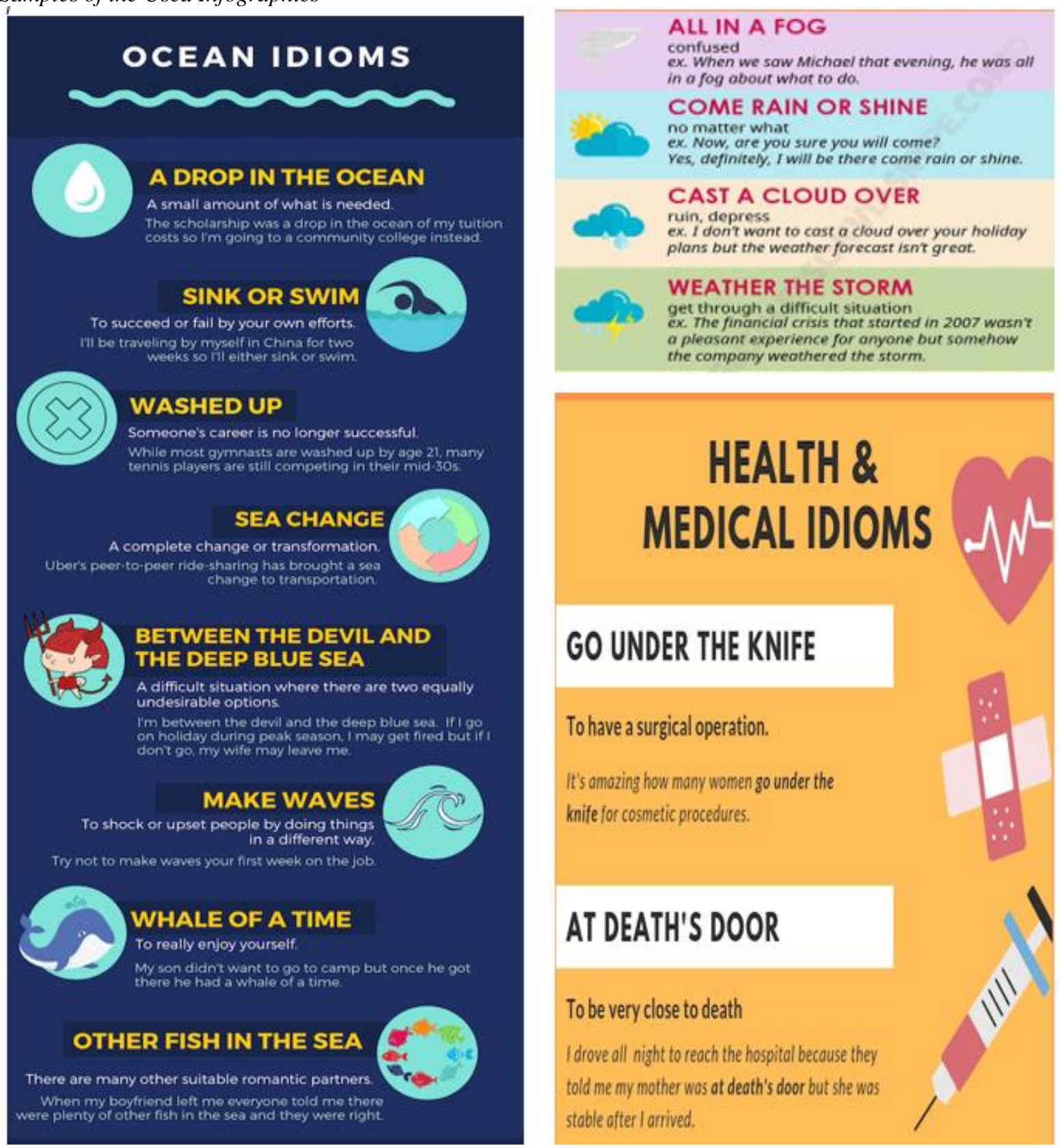

Copyright @ 2020, author, e-ISSN: 2502-6747, p-ISSN: 2301-9468 


\section{FINDINGS}

\section{Pre-test and post-test scores of the control and treatment groups}

To answer the first research question (does learning of English idioms via static infographics lead to improvement in the receptive knowledge of idioms compared to learning through texts?), descriptive statistics, paired-samples t-test, and independentsamples t-test were used. The descriptive statistics (Table 2) show that the mean scores of the pre-test for the control and treatment groups were similar $(\mathrm{M}$ $=15.08$ and 15.38 respectively). However, the posttest mean scores for the control and treatment groups increased by 4.77 and 7.21 respectively.

Table 2

Descriptive Statistics of Control and Treatment Groups Scores

\begin{tabular}{cccccc}
\hline & & \multicolumn{2}{c}{ Pre-Test } & \multicolumn{2}{c}{ Post-Test } \\
Groups & $\boldsymbol{N}$ & $\boldsymbol{M}$ & $\boldsymbol{S D}$ & $\boldsymbol{M}$ & $\boldsymbol{S D}$ \\
\hline Control & 39 & 15.08 & 4.49 & 19.85 & 6.28 \\
Treatment & 39 & 15.38 & 4.58 & 22.59 & 4.76 \\
\hline
\end{tabular}

The assumption of normality of scores distribution was tested by utilizing Shapiro-Wilk test. The test indicated a normal distribution of scores with $(p=.078)$ for the control group and $(p=$ .218) for the treatment group; thus, satisfying the assumption of normality as $(p>.05)$. To test the study hypothesis (learning English idioms by means of viewing static infographics is more effective than learning the same language construct through viewing texts), paired-samples $t$-test and independent- samples $t$-test were conducted to determine whether the mean scores of the two groups show statistically significant differences. The results of the pairedsamples $t$-test (Table 3) of the control group scores show a statistically significant difference between the mean scores of the pre- and post-test; $t(38)=$ $3.93,(p<.05)$, with a small effect size $(d=.87)$ according to the description of $d$ magnitude proposed by Plonsky and Oswald (2014). In a similar vein, the results show a statistically significant difference between the mean scores of the pre- and post-test for the treatment group; $t(38)$ $=6.84,(p<.05)$, with a large effect size $(d=1.54)$ according to the description of $d$ magnitude suggested by Plonsky and Oswald (2014).

The results of the independent-samples $t$-test (Table 4) do not show a statistically significant difference in the pre-test mean scores between the control and treatment groups; $t(76)=-.299,(p>$ .05 ). Therefore, the results confirm that both groups are homogenous with respect to prior familiarity of idioms used in this study. Conversely, the results show a statistically significant difference in the posttest mean scores between the two groups; $t(76)=-$ 2.173, $(p<.05)$. Consequently, the results suggest the rejection of the null hypothesis and acceptance of the study hypothesis. Although both groups mean scores have increased significantly; however, the small effect size $(d=.49)$, according to the description of $d$ magnitude proposed by Plonsky and Oswald (2014), in favor of the treatment group indicates a noticeable difference between the level of significance of the two groups mean scores.

Table 3

Paired-Samples t-Test Results

\begin{tabular}{lccccrr}
\hline Groups & $\boldsymbol{M}$ & $\boldsymbol{S D}$ & $\boldsymbol{t}$ & $\boldsymbol{p}$ & $\boldsymbol{d}$ & $\boldsymbol{d} \boldsymbol{f}$ \\
\hline Control & 4.769 & 7.583 & 3.928 & .000 & .87 & 38 \\
Treatment & 7.205 & 6.574 & 6.844 & .000 & 1.54 & 38 \\
\hline
\end{tabular}

Table 4

Independent-Samples $t$-Test Results

\begin{tabular}{lcccccc}
\hline Groups & $\boldsymbol{F}$ & Sig. & $\boldsymbol{t}$ & $\boldsymbol{P}$ & $\boldsymbol{d}$ & $\boldsymbol{d} \boldsymbol{f}$ \\
\hline Pre-Test & .361 & .550 & -.299 & .766 & .06 & 76 \\
Post-Test & 7.727 & .007 & -2.173 & .033 & .49 & 76 \\
\hline
\end{tabular}

\section{Learners' attitudes}

Descriptive statistics were used to answer the second research question (what are EFL learners' attitudes toward the utility of static infographics on learning English idioms?). The results (Table 5) show learners' overall agreement and satisfaction $(M=3.44, S D=0.54)$ at the utility of static infographics on learning English idioms. There is $100 \%$ agreement with items 1, 3, 5, 7 and 9. Particularly, the results show that the highest mean scores occurred with item 5, 7, and 9 respectively, as the learners perceive using infographics to learn idioms to be interesting and fun, more interesting and motivating than traditional learning through texts and dictionaries, and learners are in favour of attempting new tools such as infographics for English learning. Contrarily, the lowest mean score with the highest disagreement among all the questionnaire items occurred with item 4 with $23 \%$ of the learners, indicating that the learners perceive the association of idioms and the infographics through which they were displayed as not conducive to recalling the learned idioms. Moreover, the most responses that the learners chose among all the 4 possible choices in the questionnaire are Strongly Agree and Agree, corresponding to $49.3 \%$ and $45.6 \%$ respectively, whereas the average for Disagree corresponds to only $4.8 \%$ of the overall responses. 
Table 5

Learners' Attitudes Toward Learning Idioms Through Infographics $(n=34)$

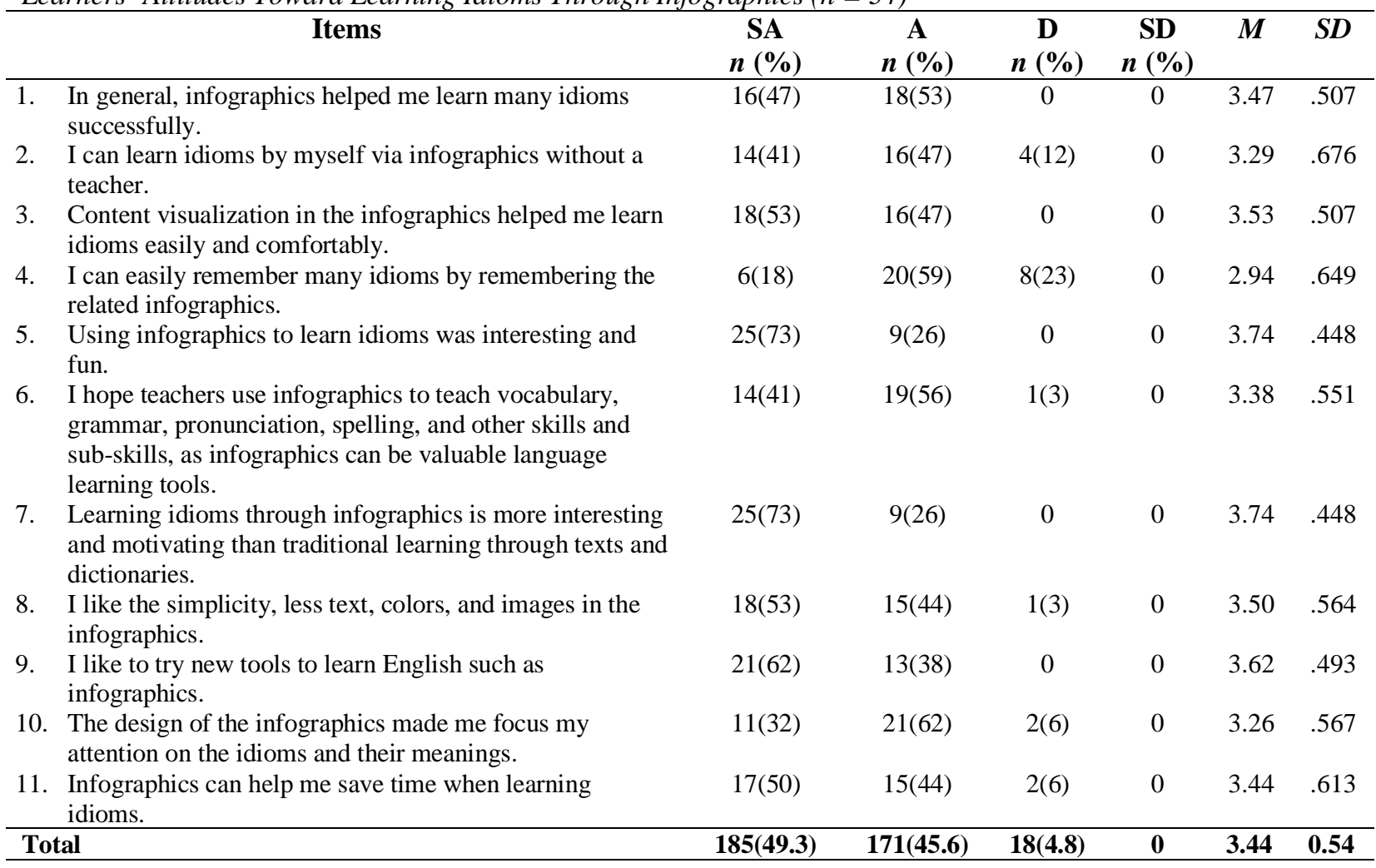

\section{Interviews}

All the interviewees reported that learning idioms via infographics was a successful experience, as the support offered by the different infographic constituents' facilitated learning. For most of the interviewees, infographics provided straightforward learning. The provided simple examples highly assisted comprehension:

S1. Infographics make learning idioms easier and make you achieve a lot. It was $100 \%$ a successful experience. I think all components of the infographics reinforce each other. For example, if images do not help, there are definitions, if definitions do not help, there are examples, and mostly it is the example that clarifies the meaning. In general, learning form the infographics was very straightforward. The examples in the infographics provided much help for learners to understand the information without using other resources.

S5. I scored higher in the second test compared to the first one...learning from infographics was straight to the point. I think learning is direct which comes from the examples because examples were very clear. Even if there were no definitions, the examples were clear; they clarify [the meaning].

Most of the interviewees stated that images in the infographics played a major role in idioms retention. Some of the interviewees mentioned that categorizing idioms into themes helped them recall idioms after the learning sessions:

S5. There is an image in mind that emerges when you look at the idioms. Because of the infographics, you recall the whole thing, you recall the idioms because of the associated images.

S6. The infographics helped me learn idioms very much. I still remember some of the idioms we learned. I remember them I think because of the colors and the images, because they attracted attention, so they stick in memory. Also, I think what helped me remember the idioms is maybe the examples and the themes of the idioms. Grouping idioms into themes helps me remember the idioms.

Learning idioms via infographics comprises viewing all the infographic constituents. The majority of the interviewees noted that by using infographics, learners can learn idioms independently. Autonomous learning is facilitated by the availability of adequate content in the infographics that suffices to successfully learn the idioms:

S4. I think learners can learn by themselves. Because the infographics provide the idioms, their definitions, how they are used in the examples. Especially that the information was presented in a simple way... and clarify things from the images. The content was enough. 
S6. First, I read the whole infographic; I read the idiom; I look at its image; I see it's explanation, for each idiom. They were easy. With infographics, you do not need any help. Because the infographics were clear in front of you and you have the idioms, examples, and the images that illustrate them. learners can read the idioms and understand right away; it was clear; there was no need for explanation. The content covers everything about the idioms.

All the interviewees emphasized that the use of infographics to learn idioms was interesting and attractive. According to half of the interviewees, it was an enjoyable experience because it is a new way of learning. Moreover, most of the interviewees noted that colors are a valuable component of the infographics, and they are important to attract attention, and half of the interviewees mentioned that limited text contributed to make the infographics enjoyable and attractive:

S1. Learning idioms by infographics was very interesting, because it is different than what we are used to in our studying. There was nothing as easy as learning from the infographics. Colors are helpful and necessary. They are catchy; catch eye sight and stimulate you to look and see what the next idiom is.

S2. The less text there is, I think it is going to be more enjoyable and easier, and one does not feel it is difficult. I think it is going to be easier and enjoyable too. The amount of text in the infographics we viewed was very excellent and enough. Colors in the infographics were very suitable and important. I noticed this with many idioms. Once we had idioms about squirrels and nuts, and I remember the background was brown; once we had idioms about garden and trees and the color was green.

Infographics motivated learners to engage in learning idioms, as the majority of the interviewees explained that the enjoyability factor that is inherent in the infographics triggers motivation for learning. Enjoyability of learning stemmed from the integration of images in the infographics compared to plain texts that are not always supportive or enjoyable:

$S 2$. I do not prefer texts. I prefer the use of images if they are available, because it makes learning more enjoyable and help you learn the idioms more than texts with just idioms and definitions. Because in texts, you do not know some words in the definitions or they are difficult to understand...Infographics motivate you much and make information easier to learn, and communicates it in an easier way. I was excited to learn in the sessions, and I wanted to know what new idioms would be.
S4. Before, when I see idioms, I feel they are difficult, I avoid them, I do not care; but, with infographics I like idioms, totally unlike before. This way is very enjoyable. The difference is the existence of the images. The images provide you with the meaning partially, if the meaning is not clear. Sometimes, in texts the definition is there, but maybe you do not understand the meaning; so, the images provide much about the meaning.

Infographic design directed learners' attention toward idioms and their meanings; thus, focusing their attention. The majority of the interviewees reported that using infographics expedites the process of learning idioms due to the simplicity of the design with images and colors increasing the simplicity, whereas $50 \%$ mentioned that the simplicity also stemmed from the nature of simple definitions and examples:

S3. I like things that are designed in a good way. So, you can say that sometimes the infographics highly fulfilled their purpose. The infographics design effectively served learning of idioms because the infographics had different colors, images, background, and everything. Infographics save time for learning idioms and their design is simple.

S4. The design was good and positive in terms of the images and idioms themselves; there were the definitions and examples. In each session, there was a different color and design. The infographics helped focus attention on the idioms and their meanings and there was no distraction... in general, the design was very helpful, different, and comfortable at the same time. Infographics were clear and simple. There are simple examples and definitions in one line which was clear and full.

\section{DISCUSSION}

The results indicate that both groups' scores increased significantly, suggesting that both materials used for learning were effective in fostering receptive knowledge of L2 idioms. Despite that the control group learned using plain texts, a limited number of texts might have facilitated successful learning and focused attention on the idioms. Furthermore, the control group results might be explained by spaced learning that occurred in small amounts in five sessions which might have influenced the learning and retention of the learned content (cf. Baddeley, 1999). Additionally, the two groups' statistically significant differences in the post-test scores might be explained by the effect of theme-based idioms learning, as idioms were presented in single themes. Provided that the qualitative findings, to some extent, confirm this explanation, it is in line with research that has 
suggested the advantage of theme-based idioms learning (e.g., Irujo, 1986).

The difference in the effect size suggests that infographics are more effective than texts with the same amount of textual content. In reference to the dual coding (Paivio, 1971, 1986) and cognitive load (Sweller, 1988; Sweller et al. 1998) theories, the different effect size might be explained by the level of information processing and the magnitude of the cognitive load that was required to learn the target idioms. That is, infographics engaged learners in active dual levels of content processing represented by verbal and visual content, suggesting additional support provided by infographics in terms of processing, comprehending, and recalling the target idioms. Moreover, the simple but facilitative design of the infographics might have reduced the extraneous load with respect to the simplicity of how the content was presented, and increased the germane load with regard to the existence of multi resources for processing, constructing, internalizing, and retrieving the input. This finding is in line with previous research that has found positive outcomes of using infographics in education in general (Islamoglu, 2015), and language learning in particular (Al Hosni, 2016).

Considering the feasible assumption that the learners in the treatment group have different learning styles and preferences when approaching a learning task, it seems that almost all students, including the non-visualizers, were supported by the help of infographics. Therefore, the findings suggest the practicality of the infographic design as it integrates visual with verbal presentations within the same tool. Moreover, textual enhancement might have added an influence on learning the target idioms. Boers et al. (2017) study showed that typographical salience in texts rendered positive outcomes in terms of multiword units retention.

When comparing infographics with plain texts, there are a number of components in infographics that enhance the presentation of information, thus resulting in a more effective and efficient learning. The above examples of infographics show how all the components that are designed to facilitate the delivery of information convey the same message to the recipient. The students exploited the verbal signs (definitions and examples) and non-verbal signs (images, shapes, and colors) simultaneously. That is, the students viewed all the constituents that refer to the same target idiom and utilized different resources to comprehend and internalize the sense of idioms. If one of the components does not assist the students to understand the meaning, then the other components can compensate and bridge this gap. On the other hand, the students who viewed the target idioms by means of texts had one resource to learn the idioms which might not suffice if the idioms are figurative.
The findings indicate learners' positive attitudes toward static infographics. In particular, learners perceive infographics as interesting, enjoyable, and more interesting and motivating than traditional learning through texts and dictionaries. Moreover, learners are in favor of attempting new tools such as infographics for English learning. These findings are in congruence with those of Akbarov et al. (2018). Furthermore, these findings are in line with Liontas (2002) who found that learners had a preference for utilizing visual materials to learn idiomatic expressions. Additionally, the findings are in harmony with those of Ozdamli et al. (2016), suggesting that presenting content via infographics increased the level of comfortableness among learners. Additionally, the findings are consistent with those of Yildirim et al. (2016) that showed that the employment of visual components increased comprehension of the content compared to viewing texts. Thus, the utility of images in the infographics might have had a strong influential role, as pointed out by Smiciklas (2012) that images processing in the human brain can occur instantly; however, text processing might demand a longer period of time.

The findings of the interviews confirm those of the questionnaire responses. In particular, the findings reveal that the constituents and adequate content of the infographics are conducive to effective learning and retention, triggering motivation and interest, promoting autonomous and efficient learning, and attracting attention. The aforementioned gains of using infographics are in harmony with Islamoglu et. al (2015), suggesting that using infographics in educational settings have positive effects on learning experiences.

In addition, the findings are in line with $\mathrm{Al}$ Hosni (2016) who found positive outcomes of using infographics in language learning. Since infographics are multimedia-based presentations, it is suggested that those form of presentations facilitates retention of the learned content as verbal and visual memories are simultaneously activated (Brunye et al., 2008). Furthermore, these findings are consistent with those of Yildirim et. al (2016), reporting that infographics and their design lend themselves well to the preferences of many learners due to the inherent visual component, and increase motivation for reading due to the limited amount of content. Since visual stimuli are major aspects of infographics, Çetin and Flamand (2013) argued that visual stimuli are assumed to facilitate retention, draw attention, and arouse interest. Emphasizing the influence of emotions in language classroom, McPherron and Randolph (2014) mentioned that appealing learning materials and an engaging environment can foster attention and improve learning. 


\section{CONCLUSION}

The findings reveal that infographics are highly effective for learning idioms and learners have positive attitudes toward the utility of infographics to tackle idioms learning. Moreover, the constituents of the infographics such as images and limited text have a positive impact on the learning process in general. Learners' experiences with idioms learning via infographics indicate effective learning and retention, high motivation and interest, independent learning and attracted attention.

Some implications can be drawn from this study: First, both modes of presenting information (verbal) and (verbal + visual) can render positive outcomes, given that learning content is limited and concise. Second, infographics seem to facilitate and promote receptive knowledge of idioms. Therefore, they are highly productive as learning tools and their utility can be extended to other difficult language constructs (e.g. phrasal verbs). Third, infographics seem to lend themselves well to a positive, enjoyable, and motivating learning environment, as new learning tools that have not been extensively exploited in the language classroom. Fourth, by and large, visualizing the learning content seems to enhance learning experiences and draw learners' attention, suggesting that more visual content might render more fruitful outcomes in language learning. Finally, future studies may investigate the effect of infographics on female EFL learners. Moreover, prospective research may examine the potential of infographics on L2 productive knowledge and on EFL learners with lower levels of English proficiency.

\section{REFERENCES}

Abbasi, A., Rohani, R., \& Zeidabadi-Nejad, R. (2015). The effect of three different methods in teaching English idioms to Iranian preuniversity students. International Journal of Educational Investigations, 2(1), 201-212.

Afify, M. K. (2018). The effect of the difference between infographic designing types (static vs animated) on developing visual learning designing skills and recognition of its elements and principles. International Journal of Emerging Technologies in Learning (iJET), 13(9), 204-223.

Akbarov, A., Gönen, K., \& Aydogan, H. (2018). Students' attitudes toward blended learning in EFL context. Acta Didactica Napocensia, 11(1), 61-68.

Al Hosni, J. (2016). The power of image in English language teaching. Journal of Teaching English for Specific and Academic Purposes, 4(1), 229-235.

Alali, F. A., \& Schmitt, N. (2012). Teaching formulaic sequences: The same as or different from teaching single words? TESOL Journal, 3(2), 153-180. https://doi.org/10.1002/tesj.13

Astika, G. (2018). Lemmatizing textbook corpus for learner dictionary of basic vocabulary. Indonesian Journal of Applied Linguistics, 7(3), 630-637.

Baddeley, A. D. (1999). Essentials of human memory. Psychology Press.

Bakla, A., C,ekic, A., \& Demiröz, H. (2016). Learning English idioms through reading in an LMS: Etymological notes versus pictorial support. Erzincan Üniversitesi Eğitim Fakültesi Dergisi, 18(1), 445-462.

Boers, F., \& Lindstromberg, S. (2009). Optimizing a lexical approach to instructed second language acquisition. Palgrave Macmillan.

Boers, F., Demecheleer, M., He, L., Deconinck, J., Stengers, H., \& Eyckmans, J. (2017). Typographic enhancement of multiword units in second language text. International Journal of Applied Linguistics, 27(2), 448-469.

Boers, F., Lindstromberg, S., \& Eyckmans, J. (2014). Some explanations for the slow acquisition of L2 collocations. Vigo International Journal of Applied Linguistics, $11,41-62$.

Bradshaw, M. J., \& Porter, S. (2017). Infographics: A new tool for the nursing classroom. Nurse Educator, 42(2), 57-59. https://doi.org/doi:10.1097/NNE.00000000000 00316

Brunye, T. T., Taylor, H. A., \& Rapp, D. N. (2008). Repetition and dual-coding in procedural multimedia presentations. Applied Cognitive Psychology, 22(7), 877-895. https://doi.org/10.1002/acp.1396

Çetin, Y., \& Flamand, L. (2013). Posters, selfdirected learning, and L2 vocabulary acquisition. ELT Journal, 67(1), 52-61. https://doi.org/10.1093/elt/ccs053

Cieślicka, A. (2006). Literal salience in on- line processing of idiomatic expressions by second language learners. Second Language Research, 22(2), 115-144. https://doi.org/10.1191/0267658306sr263oa

Hinkel, E. (2017). Teaching idiomatic expressions and phrases: Insights and techniques. Iranian Journal of Language Teaching Research, 5(3), 45-59.

Hung, B. P. (2019). A Cognitive linguistic approach to teaching English idioms to EFL students: experimental results. $3 L$ : The Southeast Asian Journal of English Language Studies, 25(2), 113-126. https://doi.org/http://dx.doi.org/10.17576/3L2019-2502-09

Irujo, S. (1986). Don't put your leg in your mouth: Transfer in the acquisition of idioms in a second language. TESOL Quarterly, 20(2), 287-304. https://doi.org/10.2307/3586545 
Islamoglu, H., Ay, O., Ilic, U., Mercimek, B., Donmez, P., Kuzu, A., \& Odabasi, F. (2015). Infographics: A new competency area for teacher candidates. Cypriot Journal of Educational Sciences, 10(1), 32-39. http://acikerisim.pau.edu.tr:8080/xmlui/handle/ $11499 / 26844$

Lamb, A., \& Johnson, L. (2014). Infographics part 1: Invitations to inquiry. Teacher Librarian, 41(4), 54-58. Language Learning, 64(4), 878912. https://doi.org/10.1111/lang.12079

Liontas, J. I. (2002). Exploring second language learners' notions of idiomaticity. System, 30(3), 289-313. https://doi.org/10.1016/S0346251X(02)00016-7

Liontas, J. I. (2015). Developing idiomatic competence in the ESOL classroom: A pragmatic account. TESOL Journal, 6(4), 621658. https://doi.org/10.1002/tesj.230

Liontas, J. I. (2017). Why teach idioms? A challenge to the profession. Iranian Journal of Language Teaching Research, 5(3), 5-25.

Liu, D. (2008). Idioms: Description, comprehension, acquisition, and pedagogy. Routledge.

Massa, L. J., \& Mayer, R. E. (2006). Testing the ATI hypothesis: Should multimedia instruction accommodate verbalizer-visualizer cognitive style?. Learning and Individual Differences, 16(4), 321-335. https://doi.org/10.1016/j.lindif.2006.10.001

McPherron, P., \& Randolph, P. T. (2014). Cat got your tongue? Recent research and classroom practices for teaching idioms to English learners around the world. TESOL Press.

Nippold, A., M., \& Taylor, L., C. (2002). Judgments of idiom familiarity and transparency: A comparison of children and adolescents. Journal of Speech, Language, and Hearing Research, 45(2), 384-391. https://doi.org/10.1044/1092-4388(2002/030)

Ozdamli, F., Kocakoyuna, S., Sahina, T., \& Akdaga, S. (2016). Statistical reasoning of impact of infographics on education. Procedia Computer Science, 102, 370-377. https://doi.org/10.1016/j.procs.2016.09.414
Paivio, A. (1971). Imagery and verbal processes. Holt, Rinehart, and Winston.

Paivio, A A.(1986). Mental representations: A dual coding approach. Oxford University Press.

Plonsky, L., \& Oswald, F. L. (2014). How big is "big"? Interpreting effect sizes in L2 research.

Schmitt, N. (2000). Vocabulary in language teaching. Cambridge University Press.

Smiciklas, M. (2012). The power of infographics: Using pictures to communicate and connect with your audiences. Que Publishing.

Sweller, J. (1988). Cognitive load during problem solving: Effects on learning. Cognitive Science, 12(2), 257-285. https://doi.org/doi.org/10.1207/s15516709cog1 202_4

Sweller, J., Van Merriënboer, J., \& Paas, F. (1998). Cognitive architecture and instructional design. Educational Psychology Review, 10(3), 251-296. https://doi.org/doi:10.1023/A:1022193728205.

Szczepaniak, R., \& Lew, R. (2011). The role of imagery in dictionaries of idioms. Applied Linguistics, 32(3), 323-347. https://doi.org/10.1093/applin/amr001

Vaez-Dalili, M., Morsagh, S., \& Shirzadi, M. (2017). Effects of contextualization, decontextualization and picture cues on learning transparent and opaque idioms by Iranian intermediate EFL learners. Journal of Applied Linguistics and Language Research, 4(6), 105-123.

Velasco, Y. P. (2016). Compositionality/noncompositionality of idioms: Non-native speakers' constraints to comprehension. Indonesian Journal of Applied Linguistics, 6(1), 135-144.

Yildirim, S., Celik, E., Yildirim, G., \& Kaban, A. (2016). ERPA International Congresses on Education (ERPA), Sarajevo, Bosnia and Herzegovina. https://doi.org/doi:10.1051/shsconf/201631010 09

Zuo, H. (2020). The effects of electronic glosses on EFL learners' noticing and retention of idioms in reading. https://doi.org/10.1007/s40299020-00517-x 